\title{
Effect of Hydrology on Fish Catch of Trawl net Fishery in the Mekong Delta
}

\section{A. VU* and N.D. NGUYEN}

Research Institute for Aquaculture II, Department of Inland Capture Fisheries, 116 Nguyen Dinh Chieu St., District 1, Hochiminh City, Vietnam.

\begin{abstract}
The Mekong River Commission monitored daily fish catches of five trawl net fishers in the Mekong delta for three years period (2003 to 2005). Hydrological parameters, including water level, discharge, and rainfall were recorded daily in the Chau Doc station. Simple linear regression was used to describe the statistical relationship between catch per unit effort (CPUE) and hydrological parameters, based on method of least squares. Catch per unit effort exhibited a strong seasonal variation, with the highest CPUE in November (wet season), when most fish move from flooded areas back to the mainstream, and lowest catch in the dry season. The peak in mean monthly CPUE lagged behind that of mean monthly hydrological parameters for a period of one to two months. Linear regression analysis showed that the mean monthly CPUE correlated most with mean monthly water level of the previous month $(\mathrm{r}=0.71 ; \mathrm{p}<0.0001)$, discharge of two previous months $(\mathrm{r}=0.72 ; \mathrm{p}<0.0001)$ and rainfall of one previous month $(\mathrm{r}=0.56 ; \mathrm{p}=0.002)$. Lateral and downstream fish migrations were believed to be the main causes affecting those relationships. Fishery regulations should, therefore, be managed in relation to hydrological regime conditions to maintain the fisheries as ecologically sustainable. Moreover, any river flow modification may be detrimental to fish stocks and, therefore, to the fisheries. As a result, any activity that regulates river flow must be taken into account.
\end{abstract}

\section{Introduction}

Seasonal flooding is a common natural feature in the lower Mekong Basin. Water level is low during the dry season (January to June); therefore, fish mainly stay in the main channels. But, water level increases at the beginning of the flood season (July to December) and creates a large flooded area, which is productive and a important feeding habitat for fish and other aquatic organisms (Sverdrup-Jensen 2002). In addition, most Mekong fish species are migratory; they migrate upstream for spawning (Poulsen et al. 2002). Their eggs and larvae drift downstream with the water current and spread out into flooded areas further downstream in Cambodia and the Mekong delta for feeding. Fish move back to the main channels at the onset of the dry season (Poulsen et al. 2004).

\footnotetext{
* Corresponding Author:

Email : amfpvn@hcm.fpt.vn
} 
Hydrological regimes influence river fisheries around the world (De Graaf et al. 1999; 2003a; Welcomme 1985, 2003; Wolter \& Menzel 2005). According to Welcomme (1975) both fish populations and catch are strongly correlated with hydrological regime in Africa floodplains. He suggested that fish catch can be predicted by calculating a regression equation based on hydrological indices (water level and river discharge) and fish production. In a later study, Welcomme (2003) observed hydrological factors, environmental degradation and fishing pressure also affect fish abundance. Similarly, inland fisheries production was strongly associated with flood pulses in Bangladesh and around the world (De Graaf 2003a).

Several studies investigating the relationship between river flow and fish catch in the lower Mekong Basin have been conducted, but mainly in Cambodia such as Zalinge et al. (2003); Hortle et al. (2004 \& 2005); Pengbun et al. (2005). They found that there was a positive relationship between fish catch and water level. Moreover, Hortle et al. (2004) show that catches of bagnet (stationary trawl net) in the Tonle Sap River in 2003 to 2004 decreased by $47 \%$ compared with high flood year (2002 to 2003), as low water level and short flooding period partly contributed to the decline during that period.

There has been an increase in conflict over water resources for hydropower, irrigation, and river navigation. Recently, the Nam Theun 2 hydropower project to construct a dam located in the lower Mekong tributary (Laos) is believed to carry significant risks in relation to the environment and social structure, but the financing for the project has been signed by the World Bank on 3 May 2005 (Starr 2005).

Identification of hydrological factors that affect fish abundance in rivers and floodplains is vital to river ecosystems for their conservation and management. Furthermore, hydrological factors can act as environmental indicators for environmental impact assessment including progress towards sustainable development. These indicators can be used to assess the ecosystem health and possibly to forecast future changes in the environment. It would be a valuable tool for both fishers and fishery managers if fish catch could be predicted in correlation with hydrological indicators.

Characteristics of most Mekong fish species are fast growth and early maturity. They are much more sensitive to changes in environmental conditions than to fishing pressure (Tran et al. 2001). Consequently, there is a need to examine the effects of hydrological regimes on fish catch to improve understanding of flood regimes in relation to fish catch in conservation and management purposes in the Mekong delta, Vietnam. Objectives of the present study were to measure the relationship between hydrological variables and fish catch of trawl net, a popular fishing gear in the Mekong delta. 


\section{Methods}

Hydrological parameters were measured on a daily basis at Chau Doc station, upper part of the Mekong delta (Fig. 1) including water level, river discharge, and rainfall. These three parameters are considered to have potential impacts on fish catch.

We monitored five trawl net fishers on a daily basis for three years period (2003 to 2005) in the Mekong delta. A data collection form was designed to gather information mainly on fishing effort and fish catch by species. Every fisher was asked to recode the information in the form before selling his/her catch to local markets.

Simple regression was used to describe the statistical relationship between a response catch per unit effort (CPUE) and one predictor (hydrological parameter). The level of relationship between dependent and independent variables were determined using the correlation coefficient (r). The strength of the correlation was determined by the "closeness" of the coefficient to \pm . The coefficient of determination value indicates the proportion of the variability in one observation that is accounted for by variability in another.

To determine the probability of a true relationship between depen-dent variable and independent variable, t-tests were performed on dependent variables (water level, river discharge, and rainfall) and independent variables(CPUE) by testing for a significant departure of the regression line slope from zero. The level of significance was 0.05 for all statistical tests. Moreover, CPUE and hydrological variables may not correlate together in the same time. Thus, lag time is taken into consideration to find the best correlation between CPUE and hydrological parameters.

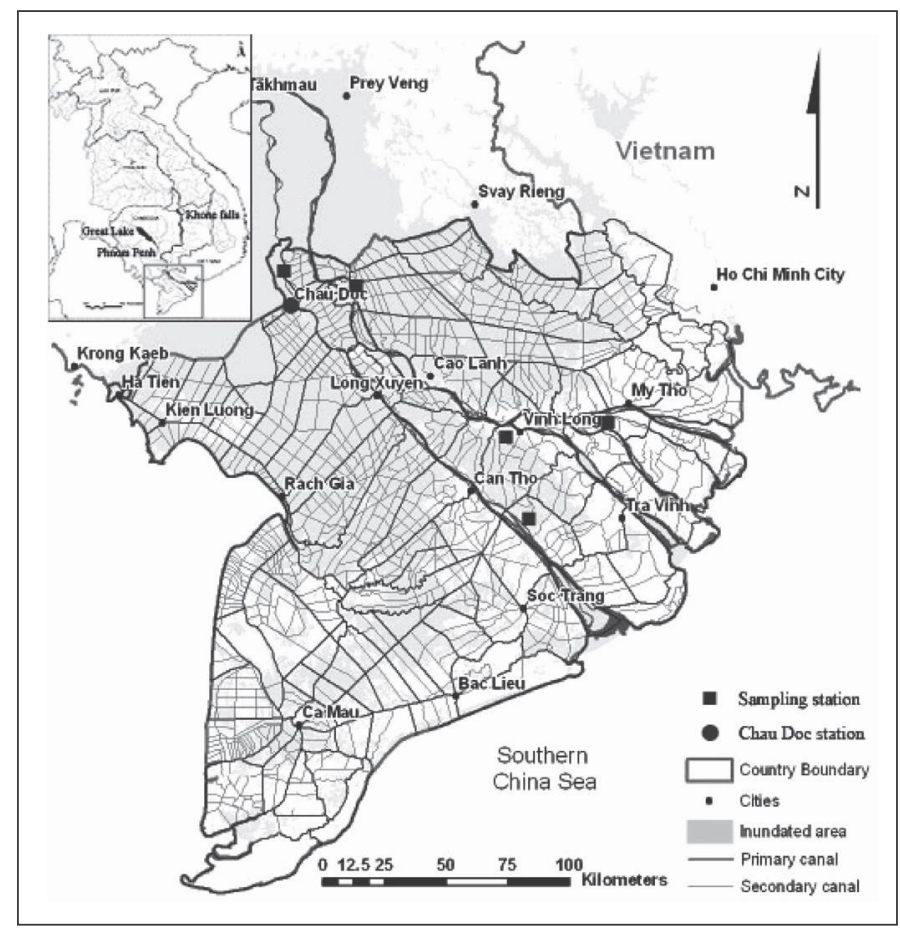

Figure 1: Sampling station in the Mekong delta 


\section{Results}

Both catch rates and hydrological parameters are seasonal. Catch per unit effort and hydrological variables correlated closely, however, the peak in CPUE lags behind that of hydrological variables for a period of one to two months (Fig. 2).
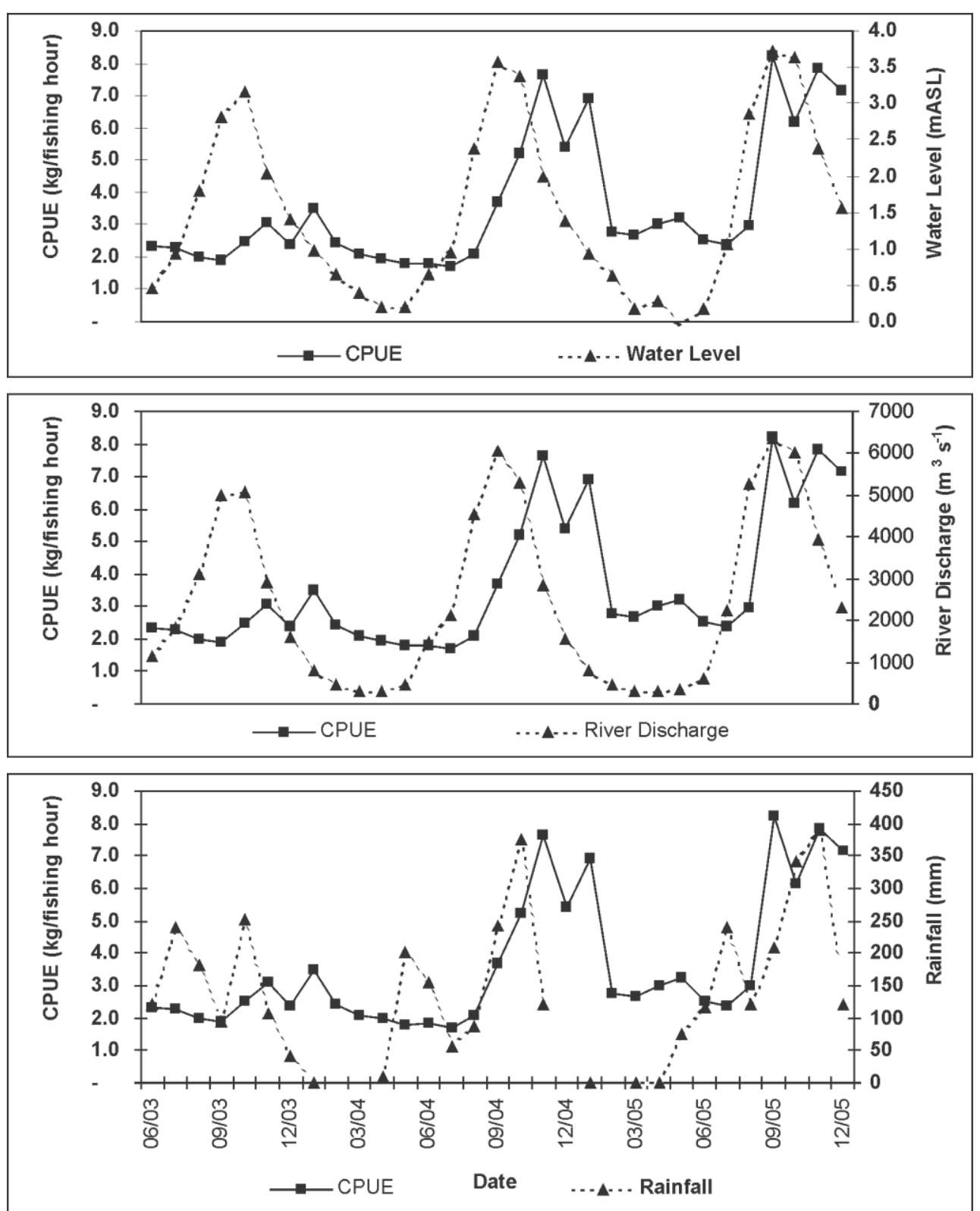

Figure 2: Comparison between mean monthly CPUE and mean monthly water level above sea level (top); river discharge (middle) and rainfall (bottom) 
A statistical representation showed that all three hydrological variables (water level, discharge, and rainfall) have a significant influence on catch rates. The level of correlation between CPUE and water level of previous month is the strongest $(r=0.71 ; p<0.0001)$ among different lag times. Similarly, there is closest relationship between CPUE and river discharge of two previous months $(\mathrm{r}=0.72 ; \mathrm{p}<0.0001)$ and correlation between CPUE and rainfall of previous month is the strongest $(\mathrm{r}=0.56 ; \mathrm{p}=0.022$; Table 1). Similarly, river discharge also has a close correlation to CPUE (Fig. 2). The CPUE correlated most with discharge of two previous months (Table 1). The level of correlation between CPUE and rainfall is weaker compared to water level and discharge due to high variation in rainfall.

Table 1. Relationship between mean monthly CPUE and mean monthly hydrological parameters of different lag times, including Pearson correlation (r) and $\mathrm{p}=$ value.

\begin{tabular}{lccc}
\hline \multirow{2}{*}{ Lag time } & \multicolumn{3}{c}{ Hydrological Parameters } \\
\cline { 2 - 4 } & Water Level & River Discharge & Rainfall \\
\hline The same month & $r=0.45 ; p=0.011$ & $r=0.36 ; p=0.046$ & $r=0.33 ; p=0.096$ \\
Previous month & $r=0.71 ; p<0.0001$ & $r=0.67 ; p<0.0001$ & $r=0.56 ; p=0.022$ \\
Two previous months & $r=0.69 ; p<0.0001$ & $r=0.72 ; p<0.0001$ & $r=0.49 ; p=0.010$ \\
Three previous months & $r=0.52 ; p=0.003$ & $r=0.61 ; p<0.0001$ & $r=0.43 ; p=0.026$ \\
Four previous months & $r=0.15 ; p=0.424$ & $r=0.31 ; p=0.086$ & $r=0.20 ; p=0.336$ \\
Five previous months & $r=-0.24 ; p=0.196$ & $r=-0.07 ; p=0.712$ & $r=0.04 ; p=0.833$ \\
\hline
\end{tabular}

\section{Discussion}

The trend of water level and river discharge are seasonal and almost the same, therefore, the linear relationship analysis showed that there was a strong relationship between water level and discharge $(r=0.98 ; p<0.0001)$ and effects of water level on the fisheries should be relatively similar to those of river discharge. Moreover, measurement of water level is easier and cheaper than that of river discharge, therefore, river discharge can be relatively predicted from water level in case of limited budget and personnel.

Maximum water level occurs in September/October while catch rates are high during the late flood season (September to December), behind the peak of water level in a period of time (one to two months). It is noted that floodplains in the Mekong delta 
are not permanently flooded but flooded only during the flood season. Fish grow quickly in flooded areas due to increased availability of food and move back to main channels (Poulsen et al. 2002). Local fishers are aware of this fish behaviour, and consequently fishing frequency at that time is very high. As a result, catch rates are seasonal and higher than that in the dry season. Therefore, the overall trends of both water level and CPUE are similar; thus, they show a strong relationship between them.

Fish catch in Bangladesh floodplain fisheries showed a strong correlation between annual yield and flood levels (De Graaf 2003a, 2003b). The yields of wet years or high water level years (1998/1999) were 20 to $25 \%$ higher than average, while the yields were only 2 to $8 \%$ of the average in extremely dry years, low water level years (1992/ 1993; De Graaf 2003a). Similarly, higher fish catch was found in the River Tocantins (a sub-basin of the Amazon basin) and in the floodplain lake on the northern bank of the Amazon River during the wet season (Cetra \& Petrere 2001; Cerdeira et al. 2000).

From the linear regression equation between CPUE and water level (CPUE $=1.2$ water level of the previous month+1.8), a decrease in water level of one metre is predicted to result in a loss of $1.2 \mathrm{~kg}$ fish per fishing hour. The model predicts a nil catch when water level declines to $1.5 \mathrm{~m}$ below sea level at the Chau Doc station. When this situation occurs, seawater may penetrate the entire Mekong delta, and freshwater fishes either die or move further upstream.

A strong positive relationship between CPUE and discharge was found, which is consistent with the results of previous studies (Schlosser and Ebel 1989, Bunt 1991, Claire et al. 1991, Growns and James 2005, Rowell et al. 2005). This is the strongest relationship among hydrological variables $(\mathrm{r}=0.72$; Table 1$)$. The most important role of river discharge is the transportation of eggs or larvae from upstream (Laos and north Cambodia) into floodplains downstream (Phnom Penh and Mekong delta). As previously noted, nearly all fish species migrate upstream to spawn at the beginning of the flood season, yet their eggs and larvae drift downstream with the water current. If the flow rates are not strong enough, eggs and larvae may not be brought into productive floodplains downstream and may be exposed to unfavourable feeding conditions in the mainstream with high water speed. During high flow conditions, the increased sediment load can contribute to higher fish production (Koponen et al. 2003). However, several studies found a negative relationship between fish catch and discharge for American shad (Alosa sapidissima; Crecco \& Savoy 1984), young-of-the-year flannel mouth sucker (Catostomus latipinnis), pink salmon (Oncorhynchus gorbuscha) and yellow stone cutthroat trout (Salmo clarkilewisi) Bulkley \& Benson 1962). It is believed that increased freshwater flow rates can cause injury to larvae and quickly push eggs or larvae back 
out to sea where they perish, accounting for a gradual decrease in their abundance.

CPUE was also positively correlated with rainfall of previous month $(\mathrm{r}=0.56$; $\mathrm{p}=0.002$ ). The first local rain, late in the dry season, is considered to be an important factor triggering fish migration for spawning (Nguyen et al. 2005). This migration may contribute to establishing the relationship between CPUE and rainfall. Also, rainfall had a positive correlation with fish catch in the Senegal River, Niger, and in the Chad Basins (Welcomme 2003).

Fish larvae depend upon seasonal flooded areas as important nursery habitats along the Mekong River. Hence, fish larvae are particularly sensitive to flooding. Unfortunately, flood controls or flood mitigation schemes are widely popular in the Mekong delta (Zalinge et al. 2003). However, these activities clearly prevent fish larvae entering the productive flooded areas. Similar results were recorded in a temperate floodplain-river ecosystem in the upper Yazoo River basin. Hydrological factors had a strong influence on fish stocks, and these factors were more important than the effect of climatic factors such as air temperature, rainfall, number of frost-free days on fish stocks (Jackson \& Ye 2000).

As discussed previously, hydrological factors of a month (m) strongly affects catch rates in the following month $(m+1$ or $m+2)$. This implies that the impact of hydrological factors on CPUE cannot result from spawning since almost Mekong species require at least one year to reach sexual maturity and entering the fishery. Moreover, catch of bagnet fishery in Cambodia is related to water level in the same year (Pengbun et al. 2005). This suggests that the impact of water level, discharge, and rainfall on spawning is less important than other factors, such as migration, for two reasons. First, maximum flood levels occur in September/October and then gradually recede, therefore all most all fish in flooded areas migrate back to the mainstream (lateral migrations). Catchability should increase at this time because of the increase in fish density. The change in hydrological factors is the main stimulus for migration and the peak of CPUE follows the peak of hydrological factors at a lag of one or two months.

Second, it is believed fish below Khone Falls and from the Great Lake (Fig. 1) migrate downstream and take about one or two months to reach the Mekong delta and then enter the fisheries. Consequently, these downstream migrations influence the relationship between CPUE and hydrological factors at a lag of one to two months. This hypothesis is based on a study which estimated 20 days for the Siamese mud carp (Cirrhinus siamensis, Cyprinidae) to migrate upstream from Phnom Penh to Khone falls (Fig. 1; Baird et al. 2003). As a result, fisheries in Vietnam are likely to depend upon Cambodia's fisheries, as many species migrate between countries. Cooperation 
between countries within the Mekong Basin should be made to manage the Mekong fisheries at sustainable exploitation levels.

\section{References}

Baird, I.G., M.S. Flaherty and B. Phylavanh. 2003. Rhythms of the river: lunar phases and migrations of small carp (Cyprinidae) in the Mekong River. Quoted In: Fisheries Bioecology at the Khone Falls (Mekong River, Southern Laos), World fish Center, (E. Baran, I.G. Baird and G. Cans 2005), pp 84.

Bulkley, R.V. and N.G. Benson. 1962. Predicting year-class abundance of Yellowstone Lake cutthroat trout. Quoted In: Correlation between annual catches of the Hilsa Shad Tennualosa ilisha in the Ganges and Indus River and rainfall two years earlier (N.N. Das, C.C. Lindsey, and M.S.Khan 1994). In: The Third Asian Fisheries Forum (ed. L.M. Chou, A.D. Munro, T.J. Lam, T.W. Chen, L.K.K. Cheong, J.K. Ding, K.K. Hooi, H.W. Khoo, V.P.E. Phang, K.F. Shim and C.H. Tan), Asian Fisheries Society, Manila, Philippines.

Bunt, D.A. 1991. Use of rod catch effort data to monitor migratory Salmonids in Wales. In: Catch Effort Sampling Strategies-Their Application in Freshwater Fisheries Management (ed. I.G. Cowx), pp. 15-32.

Cerdeira, R.G.P., M.L. Ruffino and V.J. Isaac. 2000. Fish catches among riverside communities around Lago Grande de Monte Alegre, Lower Amazon, Brazil. Fisheries Management and Ecology 7: 355-374.

Cetra, M. and M.J.R. Petrere. 2001. Small-scale fisheries in the middle River Tocantins, Imperatriz (MA), Brazil.

Fisheries Management and Ecology 8: 153-162.

Claire, D., W.K. Purvis and D. Mee. 1991. Use of telemetric tracking to examine environmental influences on catch effort indices. A case study of Atlantic Salmon (Salmo salar L.) in the River Tywi, South Wales. In: Catch effort Sampling Strategies-Their Application in Freshwater Fisheries Management (ed I.G. Cowx), pp. 33-48.

Crecco, V.A. and T.F. Savoy. 1984. Effects of fluctuations in hydrographic conditions on year-class strength of American shad (Alosa sapidissima) in the Connecticut River. Canadian Journal of Fisheries and Aquatic Sciences 41: 1216-1223.

De Graaf, G. 2003a. Dynamic of floodplain fisheries in Bangladesh, results of 8 years fisheries monitoring in the Compartmentalization Pilot Project. Fisheries Management and Ecology 10: 191-199.

De Graaf, G. 2003b. The flood pulse and growth of floodplain fish in Bangladesh. Fisheries Management and Ecology 10: 241-247.

De Graaf, G.J., A.F. Born, A.M.K. Uddin and S. Huda. 1999. Larval fish movement in the River Lohajang, Tangail, Bangladesh. Fisheries Management and Ecology 6: 109-120.

Growns, I. and M. James. 2005. Relationships between river flow and recreational catches of Australian bass. Journal of Fish Biology 66: 404-416.

Hortle, K.G., N. Pengbun, H. Rady and L. Sopha. 2004. Trends in the Cambodian dai fishery: floods and fishing pressure. Catch and Culture 10 (No.1): 7-9.

Hortle, K., N. Pengbun, H. Rady and L. Sopha. 2005. Tonle Sap yields record haul. Catch and Culture pp. 3-7.

Jackson, D.C. and Q. Ye. 2000. Riverine fish stock and regional agronomic responses to hydrological and climatic regimes in the upper Yazoo River basin. In: Management and Ecology of River Fisheries (ed I.G. Cowx), pp. 242-257.

Koponen, J., J. Sarkkula, M. Keskinen, O. Varis, S. Hellsten, E. Jarvenpaa and T. Dubrovin. 2003. Tonle Sap Development Scenario Impacts and Guidelines (Draft report).

Nguyen, T.T., N.D Nguyen, V.A. Vu and T.T. Truong. 2005. Effect of hydrology on the fish juveniles at 2 stations in the Mekong River. Journal of Mekong Fisheries, 2005: 105-131.

Pengbun, N., A. Sinath, D. Leoung, K.G. Hortle. 2005. The dai trey linh fishery on the Tonle Touch (Touch River), southeast Cambodia. Proceedings of the $6^{\text {th }}$ Technological symposium on Mekong Fisheries, Pakse, Lao PDR 26-28 November 2003, pp. 35-46. 
Poulsen, A.F., K.G. Hortle, J. Valbo-Jorgensen, S. Chan, C.K. Chhuon, S. Viravong, K. Bouakhamvongsa, U. Suntornranata, N. Yoorong, T.T. Nguyen and Q.B. Tran. 2004. Distribution and ecology of some important riverine fish species of the Mekong River Basin. MRC Technical Paper No.10.

Poulsen, A.F., O. Poeu, S. Viravong, U. Suntornranata and T.T Nguyen. 2002. Fish migrations of the lower Mekong River Basin: implications for development, planning and environmental management. MRC Technical Paper No. 8, Mekong River Commission, Phnom Penh. 62 pp.

Rowell, K., K.W. Flessa, D.L. Dettman and M. Roman. 2005. The importance of Colorado River flow to nursery habitats of the Gulf corvine (Cynoscion othonopterus). Canadian Journal of Fisheries and Aquatic Sciences 62: $2874-2885$.

Schlosser, I.J. and K.K. Ebel. 1989. Effects of Flow Regime and Cyprinid Predation on a Headwater Stream. Ecological Monographs 59 (No.1): 41-57.

Starr, P. 2005. Financing for Lao Dam Signed. Catch and Culture11(No.1): 12-13.

Sverdrup-Jensen, S. 2002. Fisheries in the Lower Mekong Basin: Status and Perspectives. MRC Technical Paper No. 6, Mekong River Commission, Phnom Penh. 103 pp.

Tran, Q.B., K. Bouakhamvongsa, S. Chan, K.C. Chhuon, T. Phommavong, A.F. Poulsen, P. Rukawoma, U.Suornratana, V.T.Doan, T.T. Truong, T.T. Nguyen, J. Valbo-Jorgensen, S. Viravong and N. Yoorong. 2001 Local knowledge in the study of fish river biology: experiences from the Mekong. Mekong Development Series No.1, 22 pp.

Welcomme, R.L. 1975. The fisheries ecology of Africa floodplains. Quoted In: Dynamic of floodplain fisheries in Bangladesh, results of 8 years fisheries monitoring in the Compartmentalization Pilot Project (G. De Graaf 2003). Fisheries Management and Ecology10: 191-199.

Welcomme, R. L. 1985. River fisheries. FAO Fisheries Technical Paper, No. 262.

Welcomme, R.L. 2003. River Fisheries in Africa: Their Relationship to Flow Regimes. Naga,World Fish Center Quarterly 26 (No. 3, July-September): 22-26.

Wolter, C. and R. Menzel. 2005. Using commercial catch statistics to detect habitat bottlenecksin large lowland rivers. River Research and Applications 21: 245255.

Zalinge, N.V., P. Degen, C.Pongsri, S. Nuov, J. G. Jensen, V.H. Nguyen and X. Choulamany 2003. The Mekong River System. Second International Symposium on the Management of Large Rivers for Fisheries-Phnom Penh, 11-14 February 2003. 